\title{
On understanding and improving the teaching of university Mathematics
}

\author{
Alan H. Schoenfeld ${ }^{1 *}$, Mike Thomas ${ }^{2}$ and Bill Barton ${ }^{2}$
}

\begin{abstract}
Background: This paper reports on a professional development workshop in University level mathematics. The workshop was grounded in Schoenfeld's (How we think. A theory of goal-oriented decision-making and its educational applications, 2010) theoretical approach, emphasizing the roles of Resources (primarily, knowledge), Orientations (primarily, beliefs), and Goals (R/O/Gs) as factors in teachers' "in the moment" decision-making. Participants characterized their R/O/Gs prior to instruction, bringing for discussion videotapes of their instruction that raised issues for them about their R/O/Gs or the choices they made during teaching.

Results: For a surprisingly large percentage of these university mathematicians, the "mathematical correctness" of what they presented was a dominant consideration, to the point where it overshadowed other considerations.

Conclusion: This gives rise to a conjectural characterization of three somewhat overlapping classes of teachers (university mathematicians, expert teachers, and proficient teachers), with the suggestion that professional development might profitably differ in the ways that it is targeted to these three groups.
\end{abstract}

\section{Introduction and overview}

Truly expert teachers bring to their teaching at least two bodies of knowledge and beliefs. On the one hand, they have deep knowledge of the topics they teach-not "just" the main ideas, but a sense of how things fit together, ideas about what is important and generative, and ideas about what is essential to get right. On the other hand, they have a rich sense of students and learning-of what students are likely to understand or misunderstand and what to do about that, and about which examples will be memorable and will help to communicate the key ideas. ${ }^{1}$ In the expert teacher (of a particular area; expertise is context-specific, of course), these two areas of knowledge blend together seamlessly and synergistically, producing pedagogical decisions that are both true to the content and pedagogically well guided.

This set of considerations is represented, in generic form, by Fig. 1 .

All teachers draw upon mathematical and pedagogical considerations to varying degrees as they teach. What one can imagine is that for any particular teacher, mathematical

\footnotetext{
* Correspondence: alans@berkeley.edu

${ }^{1}$ School of Education, University of California, EMST, Tolman Hall \# 1670,

Berkeley, CA 94720-1670, USA

Full list of author information is available at the end of the article
}

knowledge and considerations, and pedagogical knowledge and considerations, may be more or less rich and one or the other may dominate in the teacher's decision-making. This paper suggests that university mathematicians' in-themoment decision-making is significantly shaped by their mathematical knowledge and considerations. It also suggests that a form of professional development that focuses on having teachers elaborate on content considerations, what they believe is central about student learning, and their goals for instruction, can serve as a mechanism for productive reflections on teaching.

In what follows, we discuss three groups of teachers: (a) expert teachers (ETs), like those described by Ma (2010), whom we can think of as having a deep understanding of the content and pedagogy of particular subject matter, (b) university mathematicians (UM), who bring great strength of and commitment to subject matter knowledge in their teaching, and (c) proficient teachers (PT), who blend some skills and understandings from the two boxes in the middle of Fig. 1.

In the first, theoretical section of this paper, we argue that each of these three groups has distinctive characteristics that shape their in-class decision-making-characteristics that are documented in the section "Aspects of The University Mathematician's Practice". The underlying 


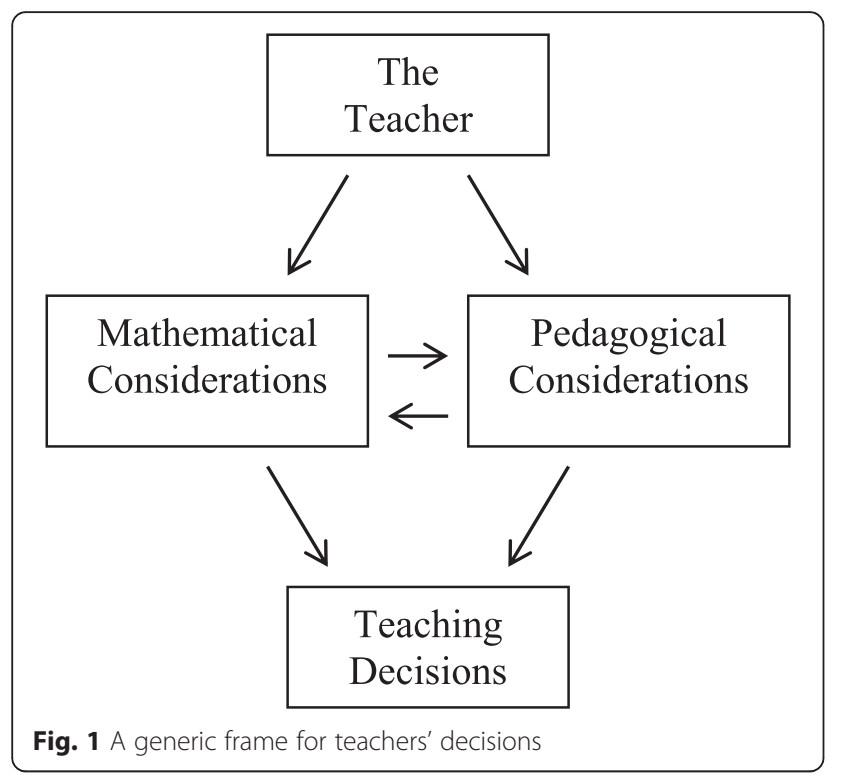

theoretical approach for this characterization is Schoenfeld's (2010) theory of teachers' decisionmaking. That theoretical perspective served as the basis for a series of pedagogical development efforts with university mathematics faculty. In those efforts, which are described in the section "The professional development model" of this paper, the core constructs in the theory-a teacher's Resources (primarily knowledge), Orientations (such as beliefs) and Goals, or $R /$ $O / G$-sometimes became the explicit focus of conversations about, and reflections upon, the faculty's teaching. As part of the professional development, observations, round table discussions and interviews with those faculty took place in the context of a supportive professional community. Ongoing conversations revealed an interesting commonality in the mathematician's orientations-what we call "effectively non-negotiable" aspects of their beliefs and orientations.

In total, this paper offers three novel contributions: a crisp framing of mathematics teachers' decision-making as suggested in Fig. 1, a discussion of how the $R / O / G$ can serve as the foundation for the pedagogical development of university faculty (section "The professional development model"), and a description of how certain aspects of their content understandings-specifically, that the mathematics they teach must be nailed down irrefutably-appear to be core to the mathematicians' pedagogy (sections "Theoretical backdrop and assertions" and "Aspects of The University Mathematician's Practice").

\section{Background}

\section{Theoretical backdrop and assertions}

Research into teaching in schools has received wide attention, but the literature characterizing the practice of university lecturers is much sparser (Speer et al. 2010), and hence, much less is known about the effectiveness of UM pedagogical approaches. A key component of developing teaching practice is deciding where to focus attention (Russ et al. 2011). Speer (2008), following teacher education practice, suggests a focus on small, but meaningful, aspects of practice, especially those related to inthe-moment lecture decisions of academic staff. One such aspect that can repay attention is an analysis of the questions used in teaching practice. In this regard, Rowland (2000) observes that the style and format of the questions used by lecturers can profoundly influence students' conceptions of what mathematics is about and how it is conducted. Hence, an analysis of the different types of questions that UMs consider important, and the reasons for asking them, can lead to the enrichment of students' understanding and appreciation of mathematics. In addition, Barton and Paterson (2009) showed the positive value to practice when teachers work on areas of their practice they have personally identified as of concern. We sought to consider these principles the present study.

There are studies, often involving both mathematics educators and UMs, that have explored the teaching of UMs in lectures (Gueudet 2015; Gueudet et al. 2014; Jaworski et al. 2009; Lew et al. 2014; Nardi 2008; Nardi et al. 2005; Petropoulou et al. 2011; Thomas 2012) and in tutorials (Mali et al. 2014). The typical "chalk and talk" lecture has been shown to be alive and well (Lew et al. 2014), and it has been suggested that the recognition of teaching intentions, goals, and actions, and the identification of teaching tools, can provide the start of a "tool box" for improving teaching (Nardi et al. 2005). Two studies that focussed on UMs' teaching goals (Jaworski et al. 2009; Thomas 2012) employed theoretical constructs that focus on the studentcentered nature of teaching. These are the spectrum of pedagogical awareness, which captures the degree to which teachers consciously engage with didactical issues to design teaching that engages students, and the teaching triad that identifies sensitivity toward students. One strategy to enhance student construction of meaning observed by Petropoulou et al. (2011) is a lecturer's use of wellchosen examples to illustrate critical characteristics of concepts. Other studies have focussed on lecturer's use of resources (Gueudet 2015; Gueudet et al. 2014), applying a documentational framework to analyze teacher involvement with sets of resources in goal-oriented activity, but without considering how this shapes practice. The issue of practice is crucial for us, in particular how UMs might gain relevant insights into teaching processes in order to develop their teaching (Jaworski et al. 2015).

In order to characterize practice-oriented professional development, we adopt the theory of decision-making described in Schoenfeld (2010). The core idea is that it is possible not only to understand but also to model a 
teacher's decisions by examining three fundamental factors:

- His/her Resources-primarily knowledge, but also including, for example, the technology in the classroom (Things are different with and without computers, clickers, etc.)

- His/her Orientations to the domain-in essence, what he or she considers important

- His/her Goals for the teaching interaction-in essence, what he or she is trying to achieve

In practice, a teacher or lecturer ${ }^{2}$ uses their orientations to establish teaching goals, both before and during a lesson or lecture. The orientations are also used to adjust to the class situation and to activate relevant knowledge. Then, decisions consistent with the goals are made, consciously or unconsciously, about the directions to pursue and the resources to use. Such in-the-moment decisions are crucial since they affect how successful the teacher will be in attaining the goals they set (Schoenfeld 2010). Modeling teachers' decision-making is not our intention here-rather, we seek practical applications of the theory, aimed at understanding and improving teaching. The question is whether a focus on a teacher's Resources, Orientations, and Goals $(R / O / G s)$ can be a productive mechanism for engaging teachers in rich conversations about their practices and, one hopes, enhancing their teaching thereby.

Our suggestion, based on data presented in the section "Aspects of the university mathematician's practice" is that for many UMs, some of the mathematical considerations in Fig. 1 are so strong as to be in effect nonnegotiable-that, in essence, instruction will not proceed unless the instructor is convinced that the mathematics being discussed is absolutely correct. We suggest that there are parallel but different considerations for the highly qualified ET, for whom deeply connected content understandings at the relevant grade levels, including understandings of what students tend to understand and have difficulty with (a.k.a. pedagogical content knowledge; see Schoenfeld (2006) and Shulman (1986, 1987)), play the driving role with regard to mathematical considerations. In both of these cases (UM and ET, which are not necessarily mutually exclusive), subject matter considerations play a powerful role in framing the ways in which the teacher considers what is essential about the mathematics that will be learned by the student. (Note, however, that these concerns can be different for the two groups.) Given this perspective, "audience" or pedagogical considerations come after content considerations-the question being, "Given what the teacher deems to be important about the mathematics, what portion of that mathematics is right for this student audience, and how does the teacher feel students should interact with it?" As described below (and speaking in generalities, of course), considerations are different for the third category, PT.

\section{On the differences between ET, UM, and PT}

Both the expert teacher and the university mathematician have a particular kind of subject matter expertise-but these differ in kind, although they are overlapping. Perhaps the best known description of expert teaching is Ma's (2010) description of Chinese teachers who have "Profound Understanding" of the content they teach-at a level relevant to their teaching. One of Ma's examples is the topic of fractions (rational numbers) and operations on them.

On the one hand, there is the formal definition of rational number, which we take from Wikipedia:

(A) “The rational numbers can be formally defined as the equivalence classes of the quotient set $(\mathbf{Z} \times(\mathbf{Z} \backslash\{0\})) / \sim$, where the Cartesian product $\mathbf{Z} \times(\mathbf{Z} \backslash\{0\})$ is the set of all ordered pairs $(m, n)$ where $m$ and $n$ are integers, $n$ is not zero $(n \neq 0)$, and " $\sim$ " is the equivalence relation defined by $\left(m_{1}, n_{1}\right) \sim\left(m_{2}, n_{2}\right)$ if, and only if, $m_{1} n_{2}-m_{2} n_{1}=0$."

On the other hand, consider the following problem, taken from Ma (2010):

(B) Imagine that you are teaching division with fractions. To make this meaningful for kids, something that many teachers try to do is relate mathematics to other things. Sometimes they try to come up with real-world situations or story-problems to show the application of some particular piece of content. What would you say would be a good story or model for $1 \frac{3}{4} \div \frac{1}{2}$ ?

The definition in (A) is "home turf" for mathematicians, who read it easily; but they might struggle to come up with 3 or 4 different stories to model different conceptions of $1 \frac{3}{4} \div \frac{1}{2}$, the simple division in (B). In contrast, the expert teachers interviewed by Ma had no difficulty producing a range of stories that represent division by fractions-but many if not most would find the definition in (A) utterly incomprehensible. The point of this example is that the teachers $\mathrm{Ma}$ studied were expert teachers of fractions - they could run rings around university mathematicians when working with children because they had broader knowledge of the mathematics at the level of engagement with children, and of children's understandings, even though the university mathematicians' knowledge of the mathematics of rational numbers is much more advanced (and abstract). That is, the ET knows a great deal about the students and content that is relevant for teaching that content effectively and in a deep way, at that particular level-but he or she 
may not have significant understanding of the content beyond that level.

At the secondary level, the PT would be the one who can, for example, explain the various equations for a line-the point-slope formula, two-intercept formula, slope-intercept formula, and so on, and show students how to use them. The expert secondary teacher would have examples at hand, tailored to what he or she knows of student understandings and misconceptions-but, he or she would also know that students tend to see the formulas as separate "rules" to be memorized and used when one encounters a particular situation (e.g., "when I have a point and know the slope, I use the point-slope formula"). Thus, ET also stresses the fact that any two pieces of information about a line enable one to determine the equation, that the formulas can be derived from each other, and that one can be flexible in deriving equations because of that fact. UM knows this, of course-and some UMs are ETs-but in general, a UM may or may not be aware of the student tendency to think of the different formulas as being fundamentally unrelated, or think to take explicit steps to correct that misunderstanding. The same can be said about more advanced topics as well. (For an example of an ET at the university level, consider George Pòlya's teaching in the film "let us teach guessing." Pòlya was, of course, a UM par excellence-and clearly an ET as well).

With this as a backdrop, we consider the three classes of teachers: UM, ET, and PT. We note that these classes can overlap, and that in particular, designations of expertise are tied to context: any teacher (UM or not) may be an ET in some content areas and a PT in others.

\section{The UM}

We introduce this section with a familiar anecdote characterizing the stereotypical mathematician. The mathematician is lecturing about a topic. He writes a preliminary lemma on the board and then says "This result is trivial to prove." At that point, he stops, pausing pensively. After a few minutes, he says "Excuse me" and leaves the room. Ten minutes later, he returns and says "Yes, it is trivial, so let's move on," continuing the lecture from where he had left off.

Putting aside the question of how we use "trivial" as a community, we wish to focus on what is essential in this anecdote: understanding the underlying mathematics is a necessary condition for the mathematician to continue. Part of what makes us mathematicians is the understanding that claims must be justified and justifiable: if we make a claim in an instructional context, we must be able to back it up. This is part of the mathematician's belief system. (That is, it is a core pedagogical orientation of the university mathematician).
In schematic form (and, obviously, generalizing and simplifying ${ }^{3}$ ), one can represent the perspective of the university mathematicians as in Fig. 2:

In short, no matter what group the UM is interacting with, that mathematician will need to feel that the mathematics is "under control." When it is, he or she can turn to the question of which mathematics is appropriate for the given audience and the appropriate form(s) of pedagogy for that group. As evidence of this phenomenon, in the section "Aspects of the university mathematician's practice," we provide examples of faculty who "stop cold" in lecture to make sure the mathematics is right-and then decide which mathematics to present to students. (Specifically, one lecturer considers sweeping details "under the rug" for a particular beginning undergraduate class, but another will make sure that his students in a beginning graduate class see the gory detail, and his struggles with it, because those students are being initiated into the world of the serious mathematician).

\section{The ET}

Consider now an expert secondary teacher, corresponding to the elementary teachers described by Ma (2010). This teacher may not have anywhere near the mathematician's knowledge of the formal mathematics-indeed, it is most unlikely that he or she would. At the same time, he or she has a kind of knowledge that UM may not - a knowledge of examples and connections that enrich the mathematics at the level of instruction and that are suited to help students develop (the beginnings of) a similarly deep understanding. As noted, an elementary school ET working on division of fractions may well have a large number of stories that represent models of

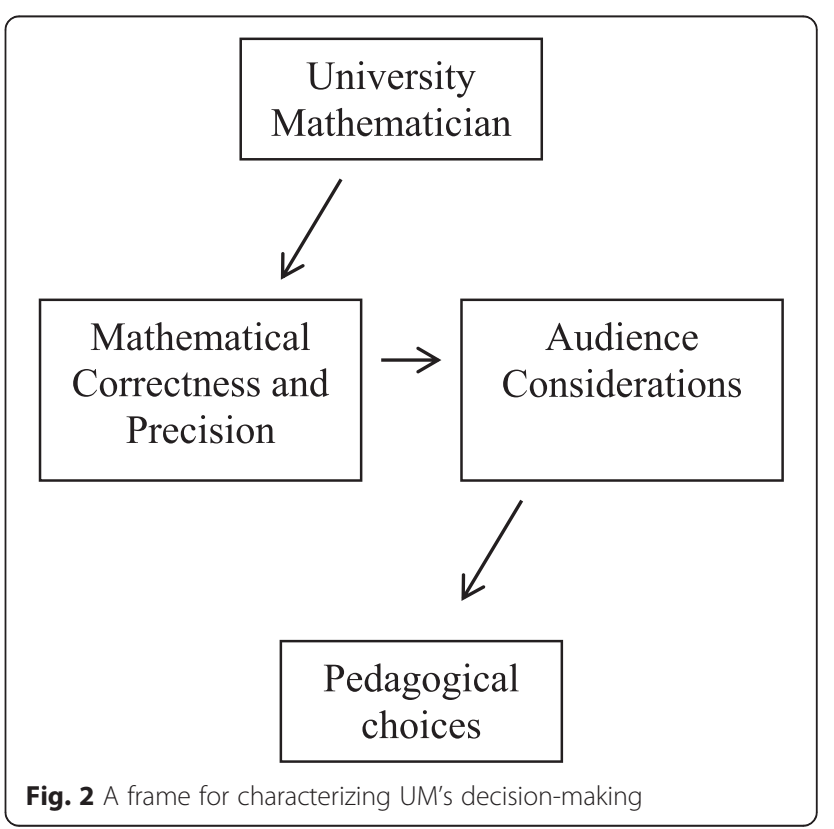


division and know contexts that would help students understand them; he or she may have ways of explaining certain rules (e.g., why it makes sense to invert the denominator and multiply by it when taking the quotient of two fractions) that are mathematically correct and that extend far beyond UM's repertoire (which includes formal ways to prove that inverting the denominator and multiplying by it is correct, but may not include explanations that are accessible to children). Similarly, the secondary ET would have a large set of contextual examples of derivatives of a function of one variable and ways of explaining limits and the limiting process. This knowledge in general has been referred to as "mathematical knowledge for teaching" or MKT (Ball et al. 2005; Ball et al. 2008; Hill and Ball 2004); the expert version of MKT was called "Profound Understanding of Fundamental Mathematics" (PUFM) by Ma (2010).

In consequence, the left-hand side of Fig. 1 looks different for expert teachers than it does for mathematicians. The mathematical considerations are of richness and connectedness, often at the grade or "horizontal" level, rather than mathematical depth (the "vertical" level). Of course, ETs will also consider requirements of the succeeding grade levels in their teaching.

Pedagogical considerations may differ as well. Like the mathematician, the expert teacher takes audience considerations into account-"This subset of what I know is appropriate for these students." In addition, he or she has a repertoire of knowledge and techniques designed to "meet students where they are" and lead them into the richness of the mathematics. ${ }^{4}$ Thus, the version of Fig. 1 that describes expert teachers looks like Fig. 3.

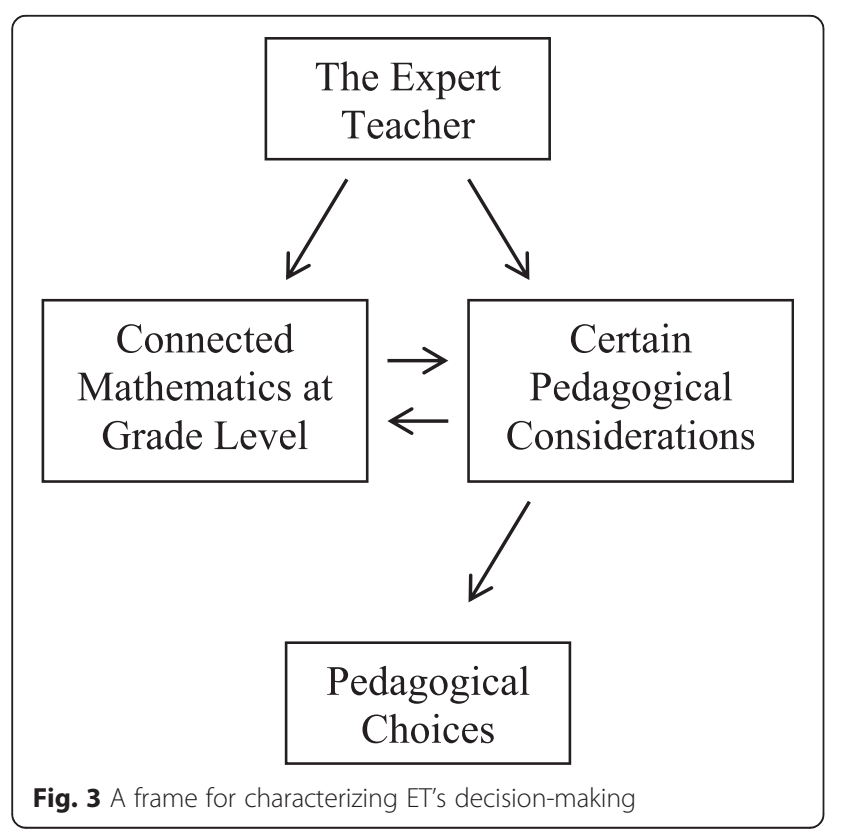

\section{The PT}

In a sense, the generic frame in Fig. 1 characterizes the proficient, but non-mathematician, non-expert teacher. For the most part, all of us, in instruction, have a certain "comfort zone"-the content about which we feel comfortable and about which are willing to go out on a limb. When we move outside that comfort zone, we tend to be more careful, and more wary-indeed, unless we are particularly adventurous, we may avoid opportunities to venture into such territory. The same is true of our pedagogy: we tend to operate within our pedagogical comfort zone, unless circumstances force us outside of it (as in the case of the mathematicians undergoing professional development in this study, who were deliberately considering new pedagogies). Hence, Fig. 1 can be modified as in Fig. 4.

From our perspective, the challenge for professional development is to find ways to help all teachers move toward both broader and deeper mathematical development (expanding their mathematical comfort zones) and to broaden and connect their pedagogical repertoires to work with that mathematical content and their growing understanding of students as learners (expanding their pedagogical comfort zones).

\section{Methods}

The professional development model

In this section, we give an account of our approach to constructing a professional development model that has the discussion of $R / O / G$ s by university mathematicians as a core strategy, and how it evolved into a project to test it in practice. In the third section, we

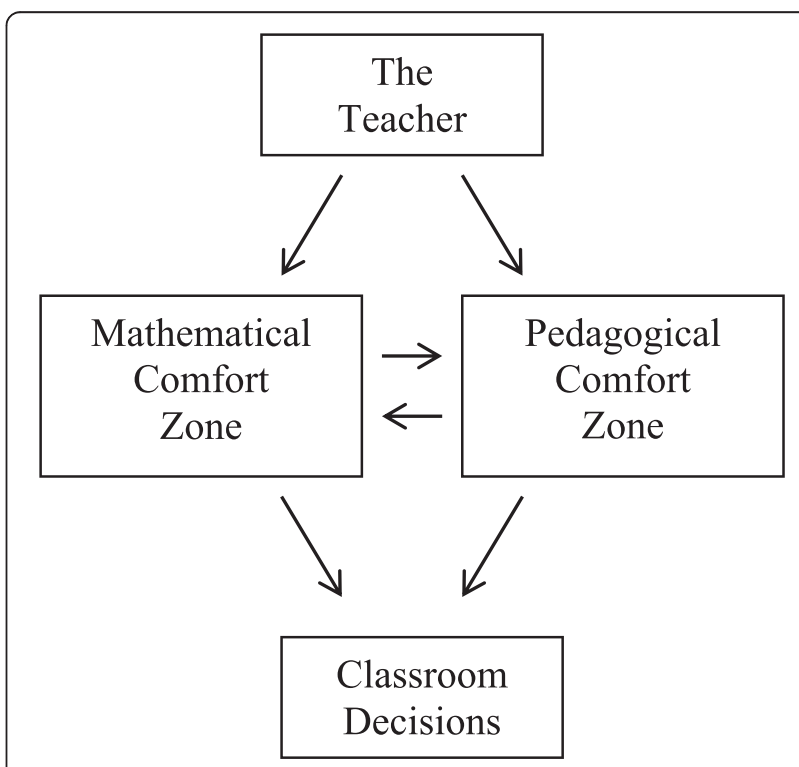

Fig. 4 A frame for characterizing teachers' decision-making in general 
provide data from an implementation of the professional development model to substantiate the claims made above.

We were guided in our search for a suitable professional development model for university mathematicians to ask whether we could use what is known about secondary teaching and its development to guide us at the tertiary level. There were, at that time, few theoretical studies of university mathematics teaching (Speer et al. 2010), a substantial amount of published opinion, and many studies that explored particular approaches. For example, Bergsten (2007) considered what constitutes the notion of quality in undergraduate mathematics teaching, concluding that in addition to mathematical exposition the factors "Teacher Immediacy" (including personal language, use of gestures and humor) and "General Criteria" (such as orchestration of subject matter teaching, cognitive activation of learners, and effective learner-oriented classroom management) are critical for high-quality teaching.

We believe that mathematics teaching at university has a distinctive character, with unique characteristics, challenges, and joys (Barton 2011; Schuck and Pereira 2011) although we acknowledge that there is much to be learned from generic studies of tertiary teaching (e.g., O’Neill et al. 2005).

For example, Kember and Kwan (2000) argue that in general, university lecturers tend to adopt either content- or learning-centered approaches to teaching (the former reflecting a focus on the content or material to be taught, the latter focusing on the learning of their students). They conclude that "Fundamental changes to the quality of teaching and learning may only result from changes to conceptions of teaching." (ibid, p. 489) - that is, that a significant change in pedagogy must come from reflection on the underlying focus of pedagogy, and an evolving view of what that focus should be. Another aspect, revealed in research on tertiary teaching in general, is that lecturers value collaborative learning in professional development, including discussions with peers (Ferman 2002). It was against this background that we looked for opportunities to develop a theory- and research-based approach to mathematics lecturer development in a systematic, collaborative manner.

In order to support university mathematicians with appropriate pedagogical professional development, we considered it important to incorporate Schoenfeld's (2010) theoretical framework characterizing decisionmaking, as outlined in the section "Theoretical backdrop and assertions". Our hypothesis was that any development process needed to assist mathematicians to be aware of the foundation of the mathematics/pedagogy dialectic that would likely occur in their practice and simultaneously, through a shift toward a more student-centered conception of teaching, build a desire for a change of practice.
During previous applications of Schoenfeld's $R / O / G$ framework to detailed analysis of teacher decision-making (Schoenfeld 2008), the researcher had inferred the teacher $R / O / G$ from classroom video. Our intention was to place the $R / O / G$ within the attention of the lecturer as a potential catalyst for developmental discussion. Originally, we intended that the lecturer would write a version of their $R / O / G$ before a lecture and would then review it afterwards, considering how it played out in practice and whether they met their goals. However, in practice, this sometimes changed, as we document below.

\section{The development process}

In any professional development (PD) model, it is important to have certain key components in place. If the group is to function in a collaborative manner, where a culture of enquiring conversation is developed (Rowland 2000), then its composition is crucial (Ferman 2002). Engaging in collaborative inquiry into, and critical reflection on, the process of teaching practice, is what makes the collective a community of inquiry (Kane et al. 2004; Wells 1999; Jaworski 2003). It was important to us to construct a group where, as part of the process of co-learning (Wagner 1997; Jaworski 2001), each member was likely to be supportive of the endeavor, and each other, and be willing and able to provide supportive feedback in a non-judgmental manner. This consideration came to the fore in constructing a group. This occurred when the four mathematics education researchers from Auckland University's mathematics department instigating the study approached four university research mathematician colleagues who they thought would be interested to join the research, in order to form a group of eight. All four, Sandy, Simon, Abi, and Mark (pseudonyms), immediately agreed to be part of the PD research. Three of them are applied mathematicians and one a pure mathematician. The research questions for the group, focused on PD, were

- How can Schoenfeld's resources, orientation and goals $(R / O / G)$ framework be adapted to support lecturer professional development?

- Can an effective lecturing professional development strategy be built around peer discussion of lecturer $R / O / G s$ matched against videoed lecturing practice?

In the initial meeting of all eight participants, an overview of the project was discussed, along with the level of individual involvement required. One of the mathematics educators then presented the idea of $R / O / G$ s, and their role in the project and a two-page summary of these ideas was given to each member of the group. This included the complexity of the dynamic relationship between knowledge, orientations, and goals and their role in setting priorities in decision-making. Following this meeting, one 
of the mathematics educators circulated an example of his $R / O / G$ for a second year lecture and this was considered. The next two meetings covered the timetable of meetings and lecture videoing along with practical project details such as who would do what and when. This included the need for one member of the group to operate the video to record the lecture and another to act as a note-taking observer. By the fourth meeting, 2 months after the first, there were two lecture videos ready to discuss.

Lecturers were encouraged to structure their $R / O / G$ using three sections, resources, orientations, and goals. Prior to each lecture, the lecturer wrote a $R / O / G$ comprising their view of the task ahead, what they considered important, their goals for the lecture, and how they thought they would accomplish them and emailed these to the rest of the group. It became clear that in writing their $R / O / G$ s, lecturers were often able to articulate their goals more clearly than their orientations. Example of goals were

- to survey those topics in number theory that are most traditionally taught at masters level. [Simon]

- to define continued fractions, to show how to compute them, and to prove some basic theoretical results. [Simon]

- to show students that interesting, unexpected things happen to the solution as the parameter changes. [Sandy]

- to show how easy it is to discover these things by using MATLAB. [Sandy]

- for the students to appreciate the appearance of Fibonacci numbers in nature. [Abi]

- to keep all the students engaged throughout the lecture. [Abi]

However, we see that these goals are not all about the content delivery but include variables such as student discovery, interest, appreciation, and engagement. Further, some lecturers such as Abi did list orientations. She said: I see this whole course partially as an exercise in "public understanding of mathematics," and Sandy's comments also record his beliefs, such as, "I hope that my slides, being based on the course-book, allow students to follow what is going on without the distraction of extensive note taking."

A second vital component in the PD model was that each person whose practice was under discussion should have complete control over all aspects of the process as it pertained to their involvement. Two members of the group chose not to be observed. In each meeting, the whole group sat around a table in a conference room to discuss the chosen segment. Each of the six who were observed chose the lectures they wanted video-recorded, and then, from a tape of the lecture, they chose a short segment (less than $5 \mathrm{~min}$ ) they felt comfortable discussing with the group, which included some aspect of instruction they wanted to discuss. We were also able to ascertain why they chose that particular section to be viewed by the group. The focus on a written $R / O / G$ prior to the lecture meant that sometimes the $R / O / G$ was evident in the choice of section that we watched, as seen in Simon's comment.

I think I disobey my $R / O / G$ and then come back to it in some sense, so that's why I picked on this...I should be able to say it's a one line proof, you guys can see that but instead I sort of get a bit too carried away in the detail, it blows out of all proportion.

Similarly, Abi's reason for choosing one video segment suggests that she was made more aware of her orientations by the $R / O / G$ emphasis. Here, she expresses her belief that while she can elicit student responses, she feels she could deal with them better and has set this as a new teaching goal.

[I] picked this segment because I'd like to maybe get some ideas on how to better deal with student responses because I'm quite good at getting them to say stuff at me now but then I don't know what to do when they do.

Thus, the $R / O / G$ was a good way to introduce the segment, enabling the lecturer to begin the discussion by orienting the group members to his/her beliefs about the content and the students, the goals for the lecture, and how well they thought it had gone. The meeting proceeded with a collective viewing of the videotape and then the lecturer was asked to comment on what had been seen. This led to a discussion of how the $R / O / G$ s had played out in practice, with the lecturer playing a major role in shaping the discussion, which was facilitated by the group organizers. The lecturer sometimes looked for group reactions ("It felt right at the time but I looked at it and thought I'm not sure about that...so I just wanted reaction, whether you have reaction to that") and sometimes they wanted to discuss the unexpected route they had taken in a lecture ("Someone asks you about something and then you go off and follow a path that you never intended to follow I suppose. That's probably why I picked it...Usually, you worry about a misconception or unpacking something if it's going to cause you trouble later, do you know what I mean. If you can function perfectly well without it, if you said well this maturity will come and ability to understand it. So the amount of effort you put into explaining something is often the function of how much effort you'd have to put in to unexplain it later.") Interestingly, they mostly chose segments about which they felt somewhat uncomfortable 
about how things went-mathematics educators tended to choose segments where their mathematical knowledge might be questioned, and mathematics researchers tended to choose moments of pedagogical concern. ${ }^{5}$ During the ensuing discussion, the mathematics educators would occasionally try to focus its direction using ideas from $R / O$ / $G$ theory. For example, in one meeting, the influence of the $R / O / G$ on decision-making was highlighted, and the lecturer, Sandy, was able to recognize that this was applicable to his lecture.

Maths educator: So these $R / O / G$ s lead to the sort of routines that we're used to so if you get a wrong answer you have some sort of routine that you use to deal with that. We talked about this, what did you say, an internal conversation in your head in order to make that decision and only you know what that was, and why you made that decision but it's clear there was a decision to be made.

Sandy: Yeah in fact my decision was based on the fact that I'd already spoken far longer than I'd planned to on the existing equation and it was time to actually go and do some problems which was supposed to be the rest of the lecture so I got onto that.

These discussions proceeded extremely well, with all members participating. Often, the content of the discussions moved considerably, ranging across pedagogical issues and mathematical topics.

After the meeting to discuss the video, each lecturer reviewed their written $R / O / G$ on the basis of the discussion and the outcomes of the lecture, appending written comments about it to the $R / O / G$. An example that shows that Sandy had reflected on the relationship between orientations, goals and decisions, writing,

I'm happy with the discussion that the DATUM group had about the video clip. The analysis of the clip is encouraging in that I gained a mathematics education perspective of the clip, which clarified in my own mind what I do when I teach. In particular, the model of teaching that [maths educator] presented in terms of a lecture being a set of goals influenced by a sequence of decisions was pertinent here. I certainly made a decision not to continue with an unexpected outcome on a graph in the first part of the lecture. Part of me wanted to address this at the time but I had already gone over time with this part of the lecture and had achieved the goals I desired.

Abi too thought about how she could improve the level of student engagement in her lecture and wrote this in her post-discussion comment on her $R / O / G$.
One that has stuck in my mind particularly, which I will use next time, is to tell all the students that they must do the computations (on calculator, phone etc.), and that I'm going to pick people out to tell me what they got (since it's such an easy calculation to do). Then if wrong answers are given, since everyone will have done the calculations, they are more likely to speak up.

Each semester, the group had at least three 1-h meetings to discuss lecture segments, prompted by prior viewing of one or two excerpts and reading the $R / O / G$ s. At these meetings, we sometimes looked at two video sections, taking half an hour for each. Overall, each of the six who were observed had at least two, and up to five, lectures discussed. Over 2 years, a total of 19 lectures were captured on video and 15 full meetings were held and transcriptions produced.

The data analysis focussed on the video of the chosen lecture segments, the transcription of the group discussion of these and the relationship between the decision points identified in the lecture segments, and the written and inferred $R / O / G$ s. One pair of researchers independently looked through the transcripts of the videos and meetings coding elements that could be inferred as part of the $R / O / G$ as well as segments that represented recurring features or ideas that we had previously identified as of interest based on the our theoretical framework (e.g., are orientations and goals involved in decision-making, and if so how?). During this process, we also encountered other areas of interest and these were also coded for later analysis. One of these emerging themes in the discussions was that related to mathematical constructs. For example, we saw the value that the applied UMs placed on recurrence relations, since it is usually what they work with, compared with the school emphasis on general formulas for a function. Following the coding, the two researchers met together and agreed on the classifications and assignments. The themes that emerged from this analysis were also followed up in the interviews.

\section{Results and discussion}

\section{Aspects of the university mathematician's practice}

In this section, we examine some of the data arising from the professional development process outlined above. Our purpose in this section is not to provide a systematic analysis of the data from the professional development sessions. Such work has been done elsewhere (see e.g., Paterson et al. 2011a, b; Paterson et al. 2011); it can serve as additional context for the present paper. Rather, our purpose is to present rather striking-but we believe, not unrepresentative-evidence from the discussions of university teaching in those professional development sessions that we believe casts light on the manner in which 
the in-lecture decision-making of a university mathematician proceeds. We suggest that what follows is representative of a particular belief structure held, to some degree, by many university mathematicians. Awareness of this aspect of university mathematicians' practice should be taken into account when designing professional development for the UM.

First, we consider the example of Simon, an experienced pure mathematician. We were able to identify a number of Simon's orientations-some he listed explicitly, others we inferred from transcripts of the group discussions and interviews with him. A number of these, given below, indicate his emphasis on the beauty and power of mathematics, and especially on the need for it to be correct.

O1: Mathematics needs to be correct. 'Oh, this is not really right, I don't like it not to be right.'

O2: Mathematical notation needs to be consistent and accurate. 'Right so the symbols $h_{j}$ over $k_{j}$ will from now on will mean precisely one of these things for the specific numbers I am interested in.'

O3: Lecture notes need to be correct and mathematically informative. 'My response after this exercise was to go away and fix the notes because they were broken' and 'it's a tricky one because the notes clearly weren't ideal because this whole thing was sort of hidden.'

O4: Some proofs are more interesting and important than others. 'The real reason I think it's a cool proof is the fact that you prove a more general result. It's one of these things that happens a lot in mathematics but you don't see it so much at the junior level.'

O5: To emphasise to students that the right theoretical tools and proof techniques can tame a mathematical problem.

O6: Students who are talented at mathematics can cope when a lecturer dwells on the finer points in mathematics. 'There is also a confidence that the students can cope with - if I go off on my own little journey the students will have the tools to deal with that ... Whereas in another class you would be worried that if I'd lost them after 15 minutes then that's it.'

O7: Traditional lecturing by dictating notes is error prone.

These orientations gave rise to a number of goals, some of which he wrote in his $R / O / G$ before the lecture, and others we were able to infer, which again emphasize mathematics, especially the importance and need for correctness of proofs in mathematics and how enjoyable they can be.

G1: to help students to understand the theory and do proofs

G2: to provide good general preparation for postgraduate study in number theory

G3: to increase the students' mathematical maturity G4: to give exposure to different proof techniques

G5: the most important theoretical part is to state and prove correctness of the recurrence formulae for computing the convergents

G6: 'I hope to give a flavour for just how neat this proof is.'

G7: to engage with the mathematics for its own sake, 'it's fun.'

G8: to ensure that the mathematics he does is 'right', part of his role as a lecturer

G9: to use notation that is consistent

G10: to induct students into thinking and behaving like mathematicians

In one of his lectures, Simon introduced a group of fourth year students to continued fractions as part of a course he describes as "...designed to be good general preparation for post-grad study in number theory." This lecture on continued fractions had a number of clear aims, as recorded in Simon's prelecture $R / O / G$ :

To define continued fractions, to show how to compute them, and to prove some basic theoretical results. The most important theoretical part is to state and prove correctness of the recurrence formulas for computing the convergents. This proof works by studying a more general problem (real coefficients). I hope to give a flavor for just how neat this proof is - it is an example of how in mathematics it is sometimes easier to prove a more general result. This fact relates to one of the themes of the course: emphasizing to the students how the right theoretical tools and proof techniques can tame a mathematical problem.

Since he considered the students to be very able, this allowed him to consider taking a "detour" during the 
lecture. Commenting on a proof of the recurrence formulae, he said "Last year there was not the same ability so I went through the proof much more lightly with them. It wasn't necessary to dwell on this particular issue of the more general result." He had originally assumed that he would simply say "Just do it" when the need for this proof arose this time. However, in the moment, the need to "get it right" and a perceived need (G10) to induct these students into the mathematician's practices won the day. This goal of Simon is in agreement with the contention of Artigue et al. (2007) that learning at this level is often seen as enculturation into advanced mathematical practices and of Ben-Zvi and Arcavi (2001) that making meaning in mathematics is about doing mathematics, which also involves socialization into its culture and values. In the event-in the middle of this proof of the recurrence formulae-he suddenly realised that there was a "notational conundrum" about to rear its head, and he was faced with an unexpected decision. Here is what he says, taken from the transcript of the lecture:

1. So, by the inductive hypothesis, I know what this... It is some $h_{i}$ over $k_{i}$.

2. I'm going to call it ... Did I give it a name? I didn't give it a name. It's just some $h_{i}$ over $k_{i}$. But whatever that $h_{i}$ over $k_{i}$ is it apparently satisfies the recurrence formula.

At this point, he stood back, paused, and looked at the board. He was clearly making a decision about whether or not to untangle the notation. The lecture transcript continues:

3. Yeah, I mean this is $a n h_{i}$ over $k_{i}$ but it's not the [italics added] $h_{i}$ over $k_{i}$ that I am really thinking of. This is a very subtle point.

4. Let's define $h_{i}$ over ... Let's define $h_{j}$ over $k_{j}$ to be these things up to $a_{j}$ where I have worked these out already all the way up to $i$... This thing I have written down here is not the $h_{i}$ over $k_{i}$ in that notation because this end term is wrong.

In a later interview, he explained what he was thinking at this point, and the decision he faced.

This is exactly the point where I suddenly realize that it is sort of not quite fitting how I was using those symbols previously. I was thinking ahead to where the proof was going and suddenly it becomes clear to me that there is a problem ahead but it's not clear to anyone else yet.

This is the point where I have made a decision. I have somehow made a decision to somehow do it right.
Oh this is not really right....at that point the whole world disappeared and it's just me and the mathematics.

The decision point is manifest here: a need for the mathematics to be clearly correct (see O1, O2 and O3) directed this university mathematician to make "a decision to somehow do it right." Only after the mathematics is correctly sorted out does he pay attention to his audience, a part of the whole world that had temporarily "disappeared". The later group's discussion of this episode, a central part of the professional development model, provided the opportunity for Simon to carry out what he called "a retrospective analysis of the situation." He chose this section of the lecture to review with the group. As his comments indicate, the UM stance regarding the importance of getting the mathematics exactly right was central in his decision-making.

I think I disobey my $R / O / G^{6}$ and then come back to it in some sense, so that's why I picked on this. So I've said in my $R / O / G$ that I assume the students are mature and independent and they're able to do things and I'm assuming the class is talented and so forth and that's all good. The proof itself is written as a sort of one line argument. I thought that I would unpack it in the lecture a little bit and I kind of got myself in a bit of a pickle because I realised somehow my notation was a bit confusing and then I sort of had this realization oh yeah that doesn't really make sense and then rather than go further and unpack it completely, so I'm disobeying my $R / O / G$, I should be able to say it's a one line proof, you guys can see that but instead I sort of get a bit too carried away in the detail, it blows out of all proportion. I realise that I've got a notation problem and I should really do more and I go back to my $R / O / G$ saying these guys should be able to figure it out.

I think I, if it was the $R / O / G$ I would have said there's a detail here but you guys can work it out yourself because the $R / O / G$ is saying they can be trusted to work out the details essentially and then I didn't. I really tried to. I thought no I'm going to labor the point.

When one of the group asked him during the discussion "How much were you being a mathematician in that moment, and how much were you being a teacher?", Simon replied:

Yeah, I think it's much more the mathematician, because I think if I was concerned about the students you'd just do it like I've done it in the notes. You'd sweep it under 
the carpet and it would all proceed right. I think it's precisely being a mathematician and going $\mathrm{mm}$... I want to make sure this is right, and so you make a big fuss out of something which is kind of...

Yeah I mean it's half trying to decide exactly how the mathematics works out and half trying to decide how much detail to go on.

The transcript makes it clear that for Simon at this point, the need for the mathematics to be correct is non-negotiable; indeed, Simon later went back to the proof to be certain he had sorted out the details for the next time (O3). During his reflection, Simon makes the point that the audience comes second: "Yeah but after a while you begin to worry about the students."

\section{A second lecturer}

Sandy, the second lecturer whose data we discuss here is an applied mathematics researcher. The first of his lectures we describe is in a third year applied mathematics class on Laplace transforms. During the lecture, Sandy presents what he calls "a number of tricks" for calculating Laplace transforms and their inverses.

In his $R / O / G$, written prior to the lecture, one sees the conflict he perceives between what the student audience will want from him and his desire to "include proofs of results if I think that seeing the proof will help the students to understand the material." Because of timing, Sandy considered leaving out a central proof that day, although his final comments "I'll leave it until the end of the lecture or perhaps I'll prove it next time" indicate the importance of this mathematics to him. The timing of the proof could be left open but it was necessary to include it, as this excerpt from the $R / O / G$ explains.

However students have an assignment due tomorrow, so they'll also be expecting me to solve some problems from their problem sheet...'ll probably have to chop something out of the lecture in order to achieve this. The obvious choice is the proof of the convolution theorem. I try to include proofs of results if I think that seeing the proof will help the students to understand the material. This is only possible for proofs that aren't too lengthy and for which the students have the background knowledge to understand them. The convolution theorem is a good example of this - it makes use of switching the order of integration in a double integral. I'll leave it until the end of the lecture or perhaps I'll prove it next time.

Sandy explained why he chose a segment from the middle of the lecture where he made an in-the-moment decision to digress from his planned path and do the proof.

I found it quite hard to choose a bit this time but this part, something unusual happened, well unusual in the sense that someone asks you about something and then you go off and follow a path that you never intended to follow I suppose. That's probably why I picked it.

The segment was related to a question response from a student. However, Sandy decided at that point to leave his plan and provide a proof.

It was just that I felt that that's quite an important mathematical idea for them to understand and so that's why I went along that path.

Yeah, I guess one of my guiding principles in teaching is that I should include proofs if I think it's going to help.

This was an unplanned, spur of the moment decision. Although considerations of how much time it would take did cross his mind, the need to have the mathematics clear won out:

I didn't actually intend to do this of course but it's the thing that happened in the lecture but I guess it does actually apply to it... It's not entirely clear, there's a trick and you get to know the trick and it's basically always going to work and it could be effective, even in the absence of understanding.

Yeah there was a bit of tension within me. I did that wondering if I had enough time to do everything else. I think to actually understand the material better they need to know this maths.

This case is not an example of "mathematics uber alles" as it seemed to be in the case of Simon, but it does indicate a strong driving force on the part of Sandy: understanding involves getting the mathematics right, and if possible, he wants students to see that (even if their use of "tricks" does get them the right answers).

In a second lecture with a second year applied mathematics class, Sandy was considering solutions of the logistic equation $x_{m}=q x_{m-1}\left(1-x_{m-1}\right)$ for various values of the parameter $q$. For a particular value of $q$, he displayed the graph using MATLAB and counted the troughs to obtain the period. The count of the period was 14, which is problematic - he knew that the correct value is 16, "...because the period doubles each time, so it goes from 2 to 4 to 8 to 16 , so... and so on, so there's a theory that actually 
says the period has to double." He counted a second time, also obtaining 14. This discrepancy between 14 and 16 was unexpected: "I guess the thing that I was probably concerned about was um... observing something that I didn't expect and not being about to explain it immediately."

In the moment, Sandy had to decide whether or not to address what is, for him, a mathematical discrepancy. The result? In Sandy's words below, we see the tension. While "part of him" wanted to address it, audience considerations, the general mathematics class not requiring it and the fact that they had "grasped the concept [of the periodicity] quite well," caused him not to follow it up.

Actually I would have liked to have pursued it a bit but we had already spent more than the allotted amount of time on this demonstration and I had shown them periodicity for shorter periods already so I think they had grasped the concept quite well so the fact that I didn't actually get a period of 16 bugged me a bit but not enough to ruin the rest of the lecture.

I certainly made a decision not to continue with an unexpected outcome on a graph in the first part of the lecture. Part of me wanted to address this at the time but I had already gone over time with this part of the lecture and had achieved the goals I desired.

One of the later discussions afforded him the opportunity to reflect further on his stance as a mathematician. His comments show that while "of course the mathematics was important," an awareness of the audience needs and his primary teaching goals took priority in that moment.

I think the teaching was actually more important than the, well of course the mathematics was important but to me, at that moment the teaching was more important I think. That was the main goal.

In this situation, with this particular audience, Sandy was happy with his decision and the way the lecture unfolded.

I'm pretty happy with the way the lecture went. Students seemed interested, in our exploration of the logistic equation and participated in the exploration.

The actual lecture itself went pretty well I was pleased with the demonstration um.. I think it was clear enough. The students were able to see what was going on.

Here again, mathematical correctness did not dominate for UM-but, it was a major issue and he revisited the unexpected outcome after the lecture to be sure he understood the mathematical basis of what happened.

\section{A third lecturer}

We have found that even when the level of the students has been taken into consideration by the UM, the need to have mathematical correctness and rigor first can tend to emerge (Paterson, Thomas, Postlethwaite, et al. 2011). In this example, we see the mathematician Abi altering her lecture, an introduction to the Fibonacci sequence, and the golden ratio for a general education first year course to provide more mathematical detail than she had initially planned. In designing the lecture, Abi used her PK to decide that these students do not need to know the mathematical details. Having introduced the students to the sequence through counting the whorls of pineapples and pinecones and providing the data to generate a table of the early Fibonacci numbers, she addresses the ratio between successive terms aiming to establish in the students' thinking that the limiting value for $f_{n+1}$ divided by $f_{n}$ is the golden ratio, $\psi$. After establishing by calculation that the value of $\frac{f_{n+1}}{f_{n}}$ oscillates about 1.6, or so, she says:

OK suppose you want to compute what this number actually is.

And it seems to be converging - and it does actually converge. [Uses the language of the UM]

So you know that $f_{n+1}$ is bigger than $f_{n}$ so this is going to be a number that is bigger than 1 .

Right? Or equal to 1. [The UM's need for precision emerges]

So ... If I am thinking about what this ratio becomes as $n$ gets really, really big.

So, for any specific $n$ these 2 things are going to be different. Right?

Because for one thing it was 1.6 and for the next one it was 1.625 .

So for any specific $n$ it's going to be different. Right? But as $n$ gets bigger and bigger and bigger these 2 things are going to get closer and closer together. Right? Yeh? [The formal idea of a limit is beyond what these students need]

So if we imagine that we're at somewhere where $n$ is really, really big these two things are going to be 
really close together. OK? So let's call that thing in both cases, we are going to say this is approximately equal to this $\psi$, approximately equal to, and this is approximately equal to $\psi$ as well. [The UM language of epsilon-delta is not here but the ideas are emerging]

As long as $n$ is big enough. So we will assume that we are in a place where $n$ is big enough then we can make these approximations. [An important qualifying statement for the UM]

Abi decided beforehand that there was no need to establish the limit $\psi$ rigorously in this class. However, her language shows that, in the moment, there emerges the need to be mathematically explicit in her terminology and to add the necessary qualifiers and conditions that rigor requires to the general statements she is making. Examples include the use of language such as "converging" and qualifying the statement "bigger than one" with "or equal to". In addition, although the formal epsilon-delta approach is not employed, these ideas begin to emerge through words such as "getting closer and closer," "really close together," and "As long as $n$ is big enough".

The rationale for this approach can be seen through Abi's response in a discussion: "So should you just ignore that corner [of important mathematics] and just hope that it's not noticed? But then is that bad because you've somehow told them something incorrect?" Here too, the importance of representing the mathematical ideas in a way that is faithful to the core (correct) mathematics is central. In a general education course, the assertion that the golden ratio occurs often in nature-and some nice pictorial demonstrations that illustrate that fact-might seem enough. However, this UM felt the need at least to reference the core mechanism of convergence.

\section{Discussion}

In this paper, we have described a general frame, represented schematically in Fig. 1, that we believe is capable of illuminating some of the reasons behind in-themoment teaching/lecturing decisions. Underpinning this frame is a tacit consideration of the $R / O / G$ of the individual; in particular, their beliefs about mathematics and pedagogy contribute to intensity of the links, represented by the arrows in Fig. 1. We have suggested that three key factors drive the decisions an instructor makes. These are the richness (depth, breadth, and connectivity) of their mathematical content knowledge (MCK), the extent of their pedagogical knowledge (PK), and the quality of the synergistic relationship between the two. In turn, the strength of these factors influences how much each of them is involved in the moment-to-moment decision- making process. In this regard, we have identified three general groups. First is the UM, where the MCK is deep and strong (reflecting, of course, a part of the UM's professional identity), but the PK may be relatively weaker, ${ }^{7}$ and the synergy between them may not be so well developed. Second is the ET, whose MCK has strength and interconnectedness at the level of the mathematics he or she teaches, and is tightly coupled with high PCK. The vibrant synergy between them leads to excellent mathematical knowledge for teaching (Hill and Ball 2004). ${ }^{8}$ Finally, there is the PT, who may have good MCK and PK along with a reasonable synergy between them.

This framework has been exemplified through three case studies of university mathematicians. In the first case, we saw that Simon's rich MCK was the driving force in his decision to make sure the mathematics was right-in order to attain his high priority goal of demonstrating the power that proof has to solve problems. For Simon, pedagogical considerations were activated second to confirm to him that the class both needed to cope with the details and was mathematically strong enough to do. Sandy was our second UM. In the first lecture discussed, Sandy's desire to make sure the mathematics was clear caused him to override the possibility that he had too much material for the lecture, resulting in a 5-min diversion from his planned lesson. In the second lecture, his rich MCK alerted him to a potential error and aroused his natural desire to require the mathematics to be correct. However, the synergy with his PK was sufficient to allow his primary lecture goals of demonstrating periodicity and the value of MATLAB as a tool to take precedence over a competing mathematical goal-to investigate further until it was evident to all that the mathematics was right. This student-centered decision was made to meet the needs of this particular class. The final case was that of Abi, who found it difficult to suppress the rigor of the mathematical details arising from the impetus of her strong MCK. However, her PK was quite well developed and the level of synergy between the two enabled her to keep the formal mathematics sufficiently in the background to accomplish her teaching goals for this class.

It stands to reason that professional development works best when it is well suited for those who receive it-meaning that it respects their values and gives them a significant role in shaping what happens. The value of the PD approach described in this paper for its intended audience, university mathematicians, can be seen in the comments of some of the UMs who took part. Simon speaks of the PD in these terms: "these activities are perfectly designed to be engaging and beneficial to the lecturers in the department." Similarly, Sandy expresses his view this way "This project is so good that I am still involved with it five years 
later." A third UM who was involved in the research speaks positively of the project in that it led to a "deeper and more sustained reflection on teaching practice." Further evidence of the effectiveness of the PD, its widespread adoption by the department that houses it, is discussed below. We hope that the detail given in the section "The development process" will support other departments in beginning to create such communities.

Before focusing on the implications of the work described here, we invoke a broad framing of learning environments that contextualizes what follows. Schoenfeld (2015) provided a characterization of the core dimensions of powerful adult learning environments. That framing is summarized in Fig. 5.

In broad terms, the PD described here can be seen to fit comfortably with the desiderata laid out in Fig. 5. The conceptualization of professionalism (dimension 1) employed in the PD is grounded in the literature on professional knowledge and decision-making. In beginning with and providing community discussions of the mathematicians' $R / O / G$ s, and the problems of practice that the mathematicians bring to the group, the PD "meets the UMs where they are" and addresses the strengths and weaknesses of their particular practice; hence, it addresses dimensions 2 and 5 productively. Given that each participant has the opportunity to shape sessions devoted to his or her teaching, there is equitable access (dimension 3); and, precisely because the participants have the opportunity to shape the conversations around things that matter to them, there is significant room for agency (dimension 4). The comments above provide some evidence of the impact.

A number of implications for professional development (PD) programs follow from our assumptions. It should be clear, vis-à-vis "meeting teachers where they are," that all PD needs to take into account the mathematical and pedagogical orientations of the practitioner. Further, the framework suggests somewhat different emphases for the three populations, UM, ET, and PT. ${ }^{9}$ To the degree that the $\mathrm{UM}$ is firmly grounded in the mathematics but perhaps less so in pedagogy, there should be a focus on key pedagogical understandings-but taking into account the mathematical context. These might include student-centered notions such as considering what the students currently understand, what the potential obstacles to furthering that understanding are, and what route through the ideas might be best to further their understanding. For the ET, PD might be best focused on the key mathematical understandings that help to complete the "big picture" of the mathematics under consideration. For example, how do the various algebraic formats of linear equations mentioned above relate to general methods for solving systems of linear equations, such as Gaussian elimination, that students will later experience? The expectation is that this enhanced mathematical awareness, in concert with the ET's pedagogical skills, result in enriched opportunities for students to see the "big picture." For the PT, the challenge is to enhance both mathematical and pedagogical understandings. For ideas about how to frame approaches to this challenge, see Schoenfeld (2014).

We propose that the insight into the influences on the pedagogical decisions of our three UMs is directly attributable to the model of PD employed in the study. This model provided an opportunity for the UMs to build an awareness of their $R / O / G$ s and its role in their decision-making. Without this PD format, such information would probably have been less visible and the PD less productive. The PD used lecturer $R / O / G$ s to initiate discussion of practice, doing so on an individual level (where the writing of the $R / O / G$ helped raise lecturer awareness of orientations and goals) and in-group discussion (where all benefited from an explicit discussion of orientations and goals, leading to personal

\begin{tabular}{|c|c|c|c|c|}
\hline $\begin{array}{l}\text { The Content } \\
\text { (Professionalism) }\end{array}$ & $\begin{array}{c}\text { Cognitive } \\
\text { Demand } \\
\text { (Room to Grow) }\end{array}$ & $\begin{array}{c}\text { Equitable Access } \\
\text { to Professional } \\
\text { Growth }\end{array}$ & $\begin{array}{l}\text { Agency, Authority, } \\
\text { and Identity }\end{array}$ & $\begin{array}{c}\text { Uses of } \\
\text { Assessment }\end{array}$ \\
\hline $\begin{array}{l}\text { The extent to } \\
\text { which the adults } \\
\text { in the } \\
\text { environment are } \\
\text { supported in } \\
\text { practices that } \\
\text { build their } \\
\text { capacity to create } \\
\text { rich learning } \\
\text { environments for } \\
\text { their students. }\end{array}$ & $\begin{array}{l}\text { The extent to } \\
\text { which adults at } \\
\text { the site are } \\
\text { coached and } \\
\text { supported in } \\
\text { ways that meet } \\
\text { them where they } \\
\text { are, and help } \\
\text { them work on } \\
\text { problems of } \\
\text { practice that } \\
\text { support their } \\
\text { growth. }\end{array}$ & $\begin{array}{l}\text { The extent to } \\
\text { which support } \\
\text { and } \\
\text { accountability } \\
\text { structures } \\
\text { enfranchise all } \\
\text { adults in the } \\
\text { environment and } \\
\text { help them grow. }\end{array}$ & $\begin{array}{l}\text { The extent to which } \\
\text { adults in the } \\
\text { environment are } \\
\text { supported in } \\
\text { developing a sense } \\
\text { of their own agency } \\
\text { with respect to } \\
\text { their growth and } \\
\text { performance. }\end{array}$ & $\begin{array}{l}\text { The extent to } \\
\text { which } \\
\text { accountability } \\
\text { structures help } \\
\text { teachers to } \\
\text { identify strengths } \\
\text { and weaknesses, } \\
\text { and help to } \\
\text { support } \\
\text { professional } \\
\text { growth. }\end{array}$ \\
\hline
\end{tabular}

Fig. 5 Five dimensions of powerful adult learning environments (from Schoenfeld 2015, p. 165, with permission) 
reflection). Sandy is typical of many UMs. He explained in his interview after the PD that other than a short course as a teaching assistant in the USA, he had received virtually no mathematics-specific pedagogical training. Since the practice of UMs involves what is in large measure a nonnegotiable stance on making sure the mathematics is right, they want PD that focuses not only on key aspects of their practice but also takes into account the mathematics. Sandy stated that the model used here provided him with the best opportunity to reflect on his practice that he had ever experienced and he offered no suggestions for how it might be improved. He was keen to continue his involvement: "I've seen how useful it is and it would be great to get other people involved as well. I'm sure I could still get more out of it if I continued...I've got no objections to being videoed...Maybe once or twice a year I suppose, I've no objections to that. Especially if I try new things in my teaching." He also presented a paper on his experience at an international conference saying "I've enjoyed being involved in mathematics education for the first time, in fact even speaking at the conference [Volcanic Delta 2011, the Eighth Southern Hemisphere Conference on the Teaching and Learning of Undergraduate Mathematics and Statistics] was enjoyable because of the positive feedback that I got...I'll continue to do that I think at other conferences in the future."

To date, the PD model we have described (see Barton et al. 2014 for a full description) has proven successful, as evidenced by the comments and teaching practice of the UMs in the department. It has provided a method of opening up the theoretical and pedagogical knowledge of mathematics education to UMs in a manner that focuses on the UMs' orientations and goals and provides them with the means to achieve their goals. We perceive the key implementation principles to be as follows.

- Use a short (3-4 min) slice of the lecture video to focus group attention and provide a sufficient springboard for discussion.

- Allow the lecturer control over selection of the lecture to be videoed, the slice of chosen, and whether it is used.

- Develop a community of inquiry (we recommend six members) based on mutual trust.

- Community composition should be homogeneous with respect to a focus on a common discipline of interest but heterogeneous across a number of variables, such as: research field (UMs and mathematics educators); UM background (pure and applied, different perspectives were in evidence on some issues); years of experience; and seniority.

- The $R / O / G$ framework is highly recommended. It was effective in developing and focusing the project and enhanced discussion.
- Encourage participants to develop awareness of their own teaching style and to use this as a catalyst for change.

(Based on Barton et al. 2014, pp. 160, 161)

There has been subsequent wider recognition in the university department where the PD model originated. The current Head of the Department stated "It has proved to be a most successful form of professional development, focusing on mathematics teaching, and the department has greatly benefited from this. [It] has reinvigorated the mathematics department's focus on quality teaching...I have appreciated the sustained and positive effect produced on the teaching culture and practice in the department over several years." Thus, the original structure of forming small heterogeneous groups comprising six to eight UMs and mathematics educators is now being employed with full departmental backing. Currently, there are two groups of six working together and all of the original UMs who participated (and were still in the department-one left for another institution) have been very happy to continue their involvement with the project, passing on their knowledge and experience to others. In addition, some who have more recently joined the program have been very happy to go on record (Paterson and Evans 2013) describing the positive benefits to their teaching of the PD they have received.

\section{Endnotes}

${ }^{1}$ There is a large literature on mathematics teachers' knowledge, heavily influenced by Shulman's $(1986,1987)$ introduction of the idea of "pedagogical content knowledge." See Schoenfeld (2006) for a review.

${ }^{2}$ Lecturers are more often called instructors in the USA.

${ }^{3}$ This may seem oversimplified almost to the point of caricature, but the evidence presented in the section "Aspects of The University Mathematician's Practice" of this paper suggests otherwise.

${ }^{4}$ We note that such repertoires are not universal. In some Asian nations, the primary mechanism for imparting information is lecturing-lecturing grounded in understandings of what causes students difficulty, what to build on, how to connect things, and so on. Expert primary and secondary teachers in English-speaking nations tend to use group work, student contributions, and such. Hence, there is no one model of "ideal" pedagogical considerations; "expertise" is culturally shaped, although student performance outcomes are the clear delineator of expert teaching.

${ }^{5}$ This speaks to the level of trust engendered in the community, which is an essential aspect of successful professional development.

${ }^{6}$ Initially, in line with the framework, we referred to Knowledge and hence $K / O / G$, rather than to Resources 
and $R / O / G$. We have updated the transcription for consistency.

${ }^{7} \mathrm{We}$ apologize if this seems to be a stereotype-but sometimes, there is truth behind stereotypes. Mathematicians are, in general, Ph.D.s; they are not necessarily extensively trained in pedagogy, though they may develop or be helped to develop deep pedagogical understandings. The three cases we presented are hardly enough to generalize from-but, they represented three out of the four UMs engaged in the PD; and, for what it's worth, the episodes described resonate with the authors' professional experience.

${ }^{8}$ Again, we note that expert teachers exist at all levels, from those expert elementary teachers described by $\mathrm{Ma}$ (2010) as having "profound understanding of fundamental mathematics" to university mathematicians like George Pólya. The categories overlap.

${ }^{9}$ It goes without saying that all PD should attend to both mathematical and pedagogical considerations. The point is that if different groups enter into PD with somewhat different orientations to both content and pedagogy, then PD should be responsive to those differences.

\section{Competing interests}

The authors declare that they have no competing interests.

\section{Authors' contributions}

All of the authors contributed to the conceptualization of the activity and report. BB, MT, and JP (see below) conducted the professional development sessions. AS, MT, and BB contributed to the writing. All authors read and approved the final manuscript.

\section{Acknowledgements}

This paper is dedicated to the memory of Judy Paterson, a valued colleague who contributed to the conceptualization and implementation of the professional development effort and who most unfortunately succumbed to cancer as the paper was being prepared.

\section{Author details}

'School of Education, University of California, EMST, Tolman Hall \# 1670, Berkeley, CA 94720-1670, USA. '2Department of Mathematics, The University of Auckland, Private Bag 92019, Auckland 1142, New Zealand.

Received: 5 September 2015 Accepted: 10 March 2016

Published online: 21 March 2016

\section{References}

Artigue, M, Batanero, C, \& Kent, P (2007). Mathematics thinking and learning at post-secondary level. In F. K. Lester (Ed.), The Second Handbook of Research on Mathematics Teaching and Learning (pp. 1011-1049). Charlotte, NC: Information Age.

Ball, DL, Hill, HC, \& Bass, H (2005). Who knows mathematics well enough to teach third grade, and how can we decide? American Educator, Fall, 14-22 and 43-46.

Ball, DL, Thames, MH, \& Phelps, G (2008). Content knowledge for teaching: what makes it special? Journal of Teacher Education, 59(5), 389-407.

Barton, B (2011). Growing understanding of undergraduate mathematics: a good frame produces better tomatoes. International Journal of Mathematical Education in Science and Technology, 42(7), 963-973.

Barton, B, Oates, G, Paterson, J, \& Thomas, MOJ (2014). A marriage of continuance: professional development for mathematics lecturers. Mathematics Education Research Journal, 27(2), 147-164. doi:10.1007/s13394-014-0134-7.

Barton, B, \& Paterson, J (2009). Teachers Learning Mathematics: Professional development research. Wellington, New Zealand: Teaching and Learning Research Initiative.
Ben-Zvi, D, \& Arcavi, A (2001). Junior high school students' construction of global views of data and data representations. Educational Studies in Mathematics, $45,35-65$.

Bergsten, C (2007). Investigating quality of undergraduate mathematics lectures. Mathematics Education Research Journal, 19(3), 48-72.

Ferman, T (2002). Academic professional development practice: what lecturers find valuable. International Journal for Academic Development, 7(2), 146-158. doi:10.1080/1360144032000071305.

Gueudet, G (2015). University teachers' resources and documentation work. Paper presented at the CERME 9 Conference, Prague, February, 2015. Downloaded from http://www.cerme9.org/products/twg14-under-construction/

Gueudet, G, Buteau, C, Mesa, V, \& Misfeldt, M (2014). Instrumental and documentational approaches: from technology use to documentation systems in university mathematics education. Research in Mathematics Education, 16(2), 139-155.

Hill, H, \& Ball, DL (2004). Learning mathematics for teaching: results from California's mathematics professional development institutes. Journal for Research in Mathematics Education, 35(5), 330-351.

Jaworski, B (2001). Developing mathematics teaching: teachers, teacher-educators and researchers as co-learners. In F.-L. Lin \& T. J. Cooney (Eds.), Making sense of mathematics teacher education (pp. 295-320). Dordrecht: Kluwer.

Jaworski, B (2003). Research practice into/influencing mathematics teaching and learning development: towards a theoretical framework based on colearning partnerships. Educational Studies in Mathematics, 54, 249-282.

Jaworski, B, Treffert-Thomas, S, \& Bartsch, T (2009). Characterising the teaching of university mathematics: a case of linear algebra. In M. Tzekaki et al. (Eds.), Proceedings of the 33rd Conference of the International Group for the Psychology of Mathematics Education (Vol. 3, pp. 249-256). Thessaloniki, Greece: PME.

Jaworski, B, Mali, A, \& Petropoulou, G (2015). Approaches to teaching mathematics and their relation to students' mathematical meaning making In K. Beswick, T. Muir, \& J. Wells (Eds.), Proceedings of $39^{\text {th }}$ Psychology of Mathematics Education Conference (Vol. 3, pp. 97-104). Hobart, Australia: PME.

Kane, R, Sandretto, S, \& Heath, C (2004). An investigation into excellent tertiary teaching: emphasising reflective practice. Higher Education, 47, 283-310.

Kember, D, \& Kwan, K-P (2000). Lecturers' approaches to teaching and their relationship to conceptions of good teaching. Instructional Science, 28, 469-490.

Lew, K, Fukawa-Connelly, T, Mejia-Ramos, JP, \& Weber, K (2014). Why advanced mathematics lectures often fail. In T. Fukawa-Connelly, G. Karakok, K. Keene, \& M. Zandieh (Eds.), Proceedings of the 17th Annual Conference on Research in Undergraduate Mathematics Education (pp. 137-151). Denver, Colorado: SIGMAA-RUME

Ma, L (2010). Knowing and teaching elementary school mathematics: teachers' understanding of fundamental mathematics in China and the United States (Anniversaryth ed.). New York: Routledge.

Mali, A, Biza, I, \& Jaworski, B (2014). Characteristics of university mathematics teaching: use of generic examples in tutoring. In P. Liljedahl, S. Oesterle, C. Nico, \& D. Allan (Eds.), Proceedings of the 38th Conference of the Int. Group for the Psychology of Mathematics Education (Vol. 4, pp. 161-168). Vancouver, Canada: PME.

Nardi, E (2008). Amongst mathematicians: teaching and learning mathematics at university level. New York, NY: Springer.

Nardi, N, Jaworski, B, \& Hegedus, S (2005). A spectrum of pedagogical awareness for undergraduate mathematics: from tricks to techniques. Journal for Research in Mathematics Education, 36, 284-316.

O'Neill, G, Moore, S, \& McMullin, B (Eds.). (2005). Emerging issues in the practice of university learning and teaching (pp. 27-36). Dublin: All Ireland Society for Higher Education (AISHE).

Paterson, J, \& Evans, T (2013). Audience insights: feed forward in professional development. In D. King, B. Loch, \& L. Rylands (Eds.), Lighthouse Delta shining through the fog, The 9th Delta Conference (pp. 132-140). Australia: Kiama.

Paterson, J, Thomas, MOJ, Postlethwaite, C, \& Taylor, S (2011). The internal disciplinarian: who is in control? In Proceedings of the 14th Annual Conference on Research in Undergraduate Mathematics Education (Vol. 2, pp. 354-368). Portland, Oregon: RUME.

Paterson, J, Thomas, MOJ, \& Taylor, S (2011a). Reaching decisions via internal dialogue: its role in a lecturer professional development model. In B. Ubuz (Ed.), Proceedings of the $35^{\text {th }}$ Conference of the International Group for the Psychology of Mathematics Education (Vol. 3, pp. 353-360). Ankara, Turkey: PME.

Paterson, J, Thomas, MOJ, \& Taylor, S (2011b). Decisions, decisions, decisions: what determines the path taken in lectures? International Journal of Mathematical Education in Science and Technology, 42(7), 985-996. 
Petropoulou, G, Potari, D, \& Zachariades, T (2011). Inquiring mathematics teaching at the university level. In. B. Ubuz (Ed), Developing mathematical thinking (Proceedings of the 35th conference of the International. Group for the Psychology of Mathematics Education), pp. 386-392. Ankara, Turkey: PME.

Rowland, S (2000). The enquiring university teacher. Philadelphia, PA: OU Press.

Russ, R, Sherin, B, \& Sherin, M (2011) Images of Expertise in Mathematics Teaching. In Y. Li and G. Kaiser (Eds), Expertise in Mathematics Instruction, pp. 41-60. New York: Springer.

Schoenfeld, AH (2006). Mathematics teaching and learning. In P. A. Alexander \& P. H. Winne (Eds.), Handbook of Educational Psychology (2nd ed., pp. 479-510). Mahwah, NJ: Erlbaum.

Schoenfeld, AH (2008). On modeling teachers' in-the-moment decision-making In A. H. Schoenfeld (Ed.), A study of teaching: Multiple lenses, multiple views (Journal for Research in Mathematics Education Monograph No. 14 (pp. 45-96). Reston: National Council of Teachers of Mathematics.

Schoenfeld, AH (2010). How we think. A theory of goal-oriented decision making and its educational applications. New York: Routledge.

Schoenfeld, AH (2014). What makes for powerful classrooms, and how can we support teachers in creating them? A story of research and practice, productively intertwined. Educational Researcher, 43(8), 404-412. doi:10.3102/0013189X1455.

Schoenfeld, AH (2015). Thoughts on scale. ZDM Mathematics Education, 47, 161-169. doi:10.1007/s1 1858-014-0662-3.

Schuck, S, \& Pereira, P (2011). What counts in mathematics education? In S. Schuck \& P. Pereira (Eds.), What counts in teaching mathematics? Self study of teaching and teacher education practices (Vol. 11, pp. 1-9). Dordrecht: Springer.

Shulman, LS (1986). Those who understand: knowledge growth in teaching. Educational Researcher, 17(1), 4-14

Shulman, L (1987). Knowledge and teaching: foundations of the new reform. Harvard Educational Review, 57, 1-22.

Speer, NM (2008). Connecting beliefs and practices: a fine-grained analysis of a college mathematics teacher's collections of beliefs and their relationship to his instructional practices. Cognition and Instruction, 26(2), 218-267.

Speer, NM, Smith, JP, \& Horvath, A (2010). Collegiate mathematics teaching: an unexamined practice. Journal of Mathematical Behavior, 29, 99-114.

Thomas, S (2012). An activity theory analysis of linear algebra teaching within university mathematics (Unpublished PhD thesis). UK: Loughborough University.

Wagner, J (1997). The unavoidable intervention of educational research: a framework for reconsidering research-practitioner cooperation. Educational Researcher, 26(7), 13-22.

Wells, G (1999). Dialogic inquiry: Towards a sociological practice and theory of education. Roskilde. Denmark: Roskilde University Centre.

\section{Submit your manuscript to a SpringerOpen ${ }^{\circ}$ journal and benefit from:}

- Convenient online submission

- Rigorous peer review

- Immediate publication on acceptance

- Open access: articles freely available online

- High visibility within the field

- Retaining the copyright to your article

Submit your next manuscript at $\gg$ springeropen.com 